\title{
Prevalence of posttraumatic arthritis following distal radius fractures in non-osteoporotic patients and the association with radiological measurements, clinician and patient-reported outcomes
}

\author{
C. M. Lameijer ${ }^{1}$ H. J. ten Duis ${ }^{1}$ - D. Vroling ${ }^{2} \cdot$ M. T. Hartlief ${ }^{2} \cdot$ M. El Moumni ${ }^{1} \cdot$ C. K. van der Sluis ${ }^{3}$
}

Received: 24 May 2018 / Published online: 13 October 2018

(c) The Author(s) 2018

\begin{abstract}
Introduction Outcomes of non-osteoporotic patients who sustained a distal radius fracture (DRF) have not gained much attention in recent literature. The aims of this study were to determine the prevalence of posttraumatic arthritis (PA), to analyze associations of radiological measurements, clinician-reported and patient-reported outcomes (CROs and PROs) with PA and gain insight into employment changes after DRF in non-osteoporotic patients.

Methods Non-osteoporotic patients following a DRF were selected. Radiographs of both wrists were obtained at follow-up and the degree of PA was determined. Radiological measurements consisted of grading of PA, ulnar variance, radial length, radial inclination, dorsal tilt, distal radio-ulnar joint width, scapholunate dissociation, step-off and gap. Active range of motion and grip strength measurements were performed and all patients filled in four questionnaires to assess pain, upper extremity functioning, and health status (Disability of Arm, Shoulder and Hand; Patient Reported Wrist Evaluation; Michigan Hand Questionnaire; Short Form-36).

Results Seventy-three patients (32 women, 41 men) with a mean age of 33.5 (SD 9.2) years were included. Prevalence of PA was $32 \%$ at a median follow-up of 62.0 months. Patients with PA had statistically significant longer radial length $(1.1 \mathrm{~mm}$, $95 \% \mathrm{CI}-2.1 ;-0.0, p=0.045)$. Patients with PA had a statistically significant diminished flexion/extension arc of motion $\left(12.0^{\circ}, p=0.008\right)$ and ulnar/radial deviation arc of motion $\left(6.3^{\circ}, p=0.018\right)$. When corrected for dominance, all grip strength measurements were not statistically significantly different between patients with and without PA. Statistically significant poorer PROs in patients with PA were the MHQ subscales general functioning (65 versus $75, p=0.018$ ), esthetics ( 94 versus $100, p=0.037$ ), satisfaction ( 75 versus $92, p=0.042$ ) and total score of the MHQ ( 83 versus $91, p=0.044$ ), as well as the SF-36 subscale physical functioning ( 95 versus $100, p=0.028$ ). In regression analyses the DASH, PRWE function and PRWE total were statistically significantly associated with flexion/extension arc of motion. Seven patients (10\%) changed or left their occupation because of the DRF.

Conclusion Non-osteoporotic patients had a considerably high prevalence of PA following DRFs, despite a relatively short follow-up time. Patients with longer radial length more often had PA. Irrespective of AO/OTA fracture type, patients with PA had diminished range of motion, but no altered grip strength measurements. Non-osteoporotic patients following DRFs perceived diminished general functioning and dissatisfaction, which was impacted by the diminished active range of motion. Pain or impaired general health status was not reported. The PRO MHQ might be a valuable evaluation tool in this patient group. Change of occupation following DRFs should receive attention in further research.
\end{abstract}

Keywords Wrist · Distal radius · Posttraumatic arthritis · Patient-reported outcome

\section{Introduction}

The development of posttraumatic arthritis (PA) following distal radius fractures (DRFs) has been described

C. M. Lameijer

C.M.Lameijer@UMCG.nl

Extended author information available on the last page of the article in populations with a wide range in age and follow-up time [1]. Clinical studies have supported the hypothesis that an increasing age is an important risk factor for the 
development of PA [2]. However, already in non-osteoporotic patients the prevalence of PA following DRFs has been described as high as 43-50\% [3, 4]. Since DRFs in young non-osteoporotic patients usually result from high energy trauma, these injuries often have intra-articular involvement [5]. This can result in residual articular incongruence, which is usually described in step-offs and gaps [6-11]. Intercarpal ligamentous injuries, radiologically reflected in the distance between scaphoid and lunate (SL ligament injury) and distal radio-ulnar joint instability are also associated with DRFs [5, 12, 13]. Conflicting results have been reported in literature with regard to other radiological parameters and their association with the development of PA in heterogeneous cohorts [4-6, $11,14]$. PA following a DRF has been associated with diminished clinician reported outcomes (CROs), such as active range of motion and strength measurements, in populations with wide age ranges $[4-6,15,16]$. Also, an association between PA following DRF and poorer patientreported outcomes (PROs), assessed by the Short Form Health Survey 36 (SF-36) in patients with an age range of 24-93 years has been reported [17]. Other studies did not find an association between PROs and PA [18-20]. Literature suggests that patients with pre-existing osteoporosis who sustained a DRF have better PROs than those without osteoporosis [21, 22]. In addition to pre-existing osteoporosis, age seems to be an independent factor influencing PROs following DRFs [2].

Few studies report on non-osteoporotic study populations following DRFs [23, 24]. As a consequence, limited information is available on the long-term outcomes of non-osteoporotic patients following a DRF. Although high prevalence of PA is reported in literature in non-osteoporotic patients after DRF, associations with CROs and PROs remain unclear. We hypothesized that PA following DRFs in non-osteoporotic patients may have greater impact because an active (working) life may pose higher demands on wrist function compared to older patients. Therefore, insight in the association between radiological measurements and PA and the association between PA and wrist function, activity performance, pain, satisfaction, quality of life in these young patients is mandatory. This knowledge could be used to direct rehabilitation treatment and to inform young patients on outcomes and influence on societal roles (e.g. occupation) they can expect in the long-term.

\section{Objectives}

The aims of this study were to determine the prevalence of PA, and to analyze associations of radiological measurements, CROs and PROs with PA and gain insight in employment changes following a DRF in non-osteoporotic patients.

\section{Methods}

This retrospective cohort study was approved by the Medical Ethics Committee (NL41587.099.13) and registered at the Dutch Trial Bureau (TC 4002). Before entering the study, participants signed an informed consent form. From a level II trauma center database, we selected all patients of a non-osteoporotic age group (men, 18-50 years and women, 18-40 years old, at the time of injury) who sustained a DRF between January 2005 and January 2011 and were treated both non-surgically or surgically [25-27]. Exclusion criteria were fractures treated surgically after the 7 th day following injury, open fractures, pre-existing osteoarthritis or risk factors for early osteoporosis (steroid use, alcoholism or early menopause, low body weight), because outcomes in these patients might not be representative for young non-osteoporotic patients following a DRF. A total of 433 patients fulfilled the inclusion criteria and received an invitation to participate in the study. A notification of changed home address was received from 43 participants, but current addresses could not be retrieved. From 306 patients, no response was received. Eighty-four patients responded of which 73 (32 women, 41 men) consented to participate. All eligible patients were invited for a single visit to the rehabilitation department. One hand therapist measured CROs (active range of motion and grip strength). Patients also filled in four PROs at the time of their visit. At the time of the participants' visit, lateral (Lundy) and posteroanterior (PA) wrist radiographs were made of both wrists. All radiographs were evaluated by a single radiologist specialized in musculoskeletal disorders with a special interest in hand and wrist anatomy. PA was classified according to the grading system as described by Knirk and Jupiter: $0=$ no signs of PA, $\mathrm{I}=$ slight joint-space narrowing, II = marked joint-space narrowing and osteophyte formation, III = bone-on-bone, osteophyte and cyst formation [1]. Further radiological parameters were measured according to the technique described by Kreder et al.; ulnar variance, radial length, radial inclination and dorsal angulation (Fig. 1) and step-off and gap (Fig. 2) [28, 29]. In addition, the scapholunate distance (SL distance) and the distal radio-ulnar joint (DRUJ) space were measured [30]. Normal ranges for radiological factors have been previously described; ulnar variance -4 to $2 \mathrm{~mm}$ [31, 32], radial length $8-17 \mathrm{~mm}$ [31], radial inclination $16^{\circ}-29^{\circ}$ $[33,34]$, dorsal angulation 0 -palmar $22^{\circ}[35,36]$. In addition, to correct for anatomical variation between patients, measurements of the uninjured wrist were obtained at follow up and used as a reference to interpret measurements of the injured wrist. 


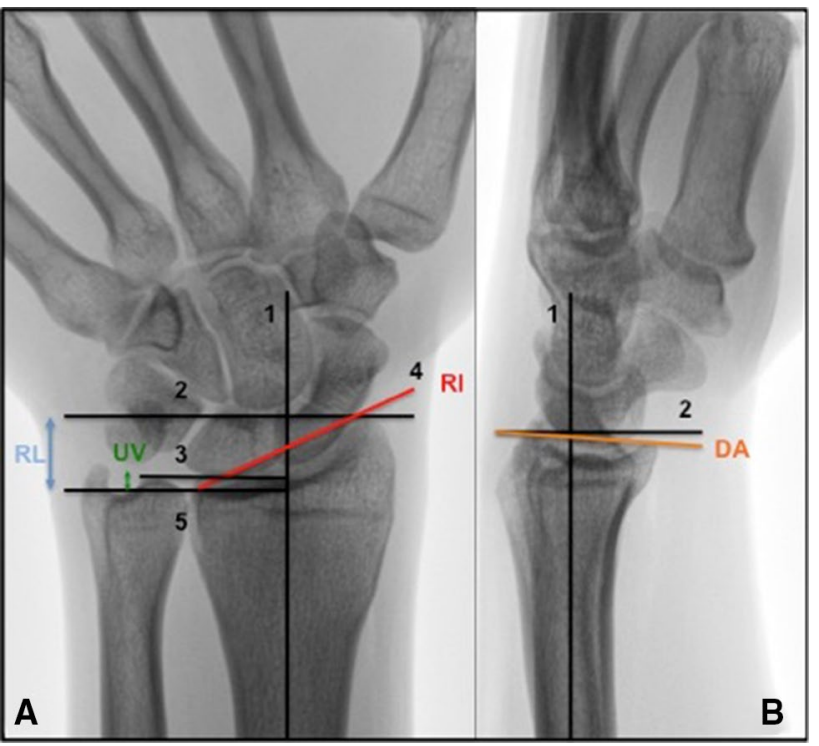

Fig. 1 a Posteroanterior measurement guidelines: (1) The center of the radial shaft is determined at $3 \mathrm{~cm}$ and $5 \mathrm{~cm}$ below the midregion of the proximal lunate articular surface. This line represents the central axis of the radius. (2) A line perpendicular to the central long axis of the radius is drawn at the level of the most distal aspect of the radial articular surface. (3) A line perpendicular to the central long axis of the radius is drawn at the level of the ulnar margin of the distal radial articular surface. (4) The radial and ulnar margins of the distal radial articular surface are connected. (5) A line perpendicular to the central long axis of the radius is drawn at the level of the distal ulnar articular surface. b Lateral measurement guidelines: (1) The center of the radial shaft is determined at $3 \mathrm{~cm}$ and $5 \mathrm{~cm}$ below the mid-region of the proximal lunate articular surface. This line represents the central long axis of the radius. (2) A line perpendicular to the central long axis of the radius is drawn at a convenient level. (3) The dorsal and anterior margins of the distal radial articular surface are connected. $U V$ ulnar variation, $R L$ radial length, $R I$ radial inclination, $D T$ dorsal tilt

\section{CROs: active range of motion and grip strength}

The participants were positioned sitting at a table, with hips and knees flexed $90^{\circ}$. Elbows were positioned on the table and flexed in $90^{\circ}$ with wrists in neutral position. A digital protractor of Biometrics LTD and E-Link ${ }^{\circledR}$ software was used to measure active range of motion. Flexion/extension arc of motion, ulnar/radial deviation arc of motion and supination/pronation arc of motion were measured in degrees. Grip strength and sustained grip strength were measured in kilograms using a digital Jamar dynamometer and key pinch strength using a pinch meter of Biometrics LTD and E-Link ${ }^{\circledR}$ software. For people with right sided dominance it is known that the right hand has $10 \%$ more grip strength in comparison to the left hand. This is not the case when people are left sided dominant; grip strength in both hands is similar [37]. Therefore, a correction for grip strength measurements was performed to correct for right sided dominance. Grip

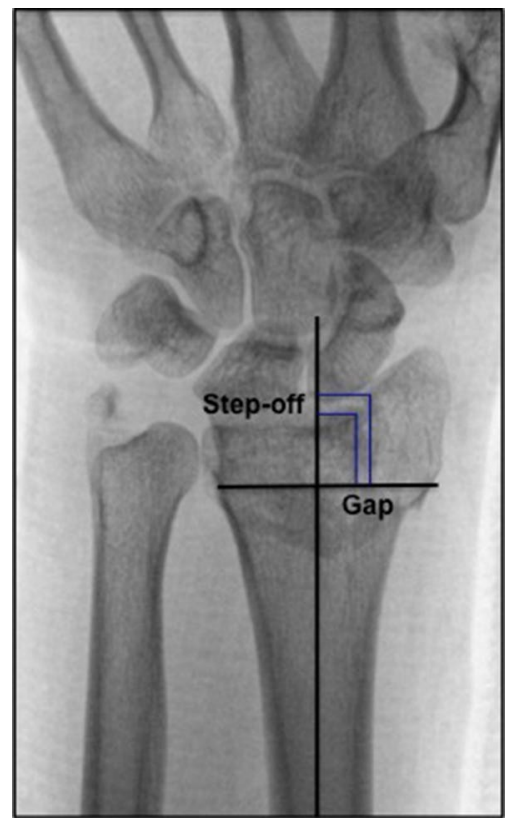

Fig. 2 Step-off and gap measurement. (1) Step-off at the articular surface of the distal radius was measured parallel to the central long axis of the radius by drawing perpendicular lines from the most distal margin of each side of the articular incongruence. (2) Gap deformity was measured along a perpendicular line to the central long axis of the radius

strength of the injured wrist was calculated as a percentage of the uninjured wrist to correct for variation between patients. For assessing sustained grip strength, patients were asked to grip as hard as possible during a $30 \mathrm{~s}$ period, the average grip strength (kilograms), computed over the last $18 \mathrm{~s}$ of this 30 -s period was recorded. Key pinch strength measured in kilograms was derived from the maximum peak strength sustained during at least $2 \mathrm{~s}$. The mean of three performances was presented for all strength measurements. First, all active range of motion measurements were recorded. Subsequently grip strength, sustained grip strength and key pinch strength were assessed in consecutive order, alternating dominant and non-dominant sides.

\section{PROs: DASH, PRWE, MHQ, SF-36}

All patients completed 4 questionnaires involving pain scores, specific upper extremity functioning, and health status.

The Disability of Arm, Shoulder and Hand (DASH) Questionnaire is a 30-item self-report measure assessing physical functioning and symptoms of the upper limb. DASH-scores range from 0 to 100 (higher scores indicate worse function). The DASH has a good validity, reliability and responsiveness in upper extremity disability assessment $[38,39]$. 
The Patient Rated Outcome Evaluation (PRWE) is a 15-item questionnaire divided into two subscales: pain (5 items) and function (10 items). The PRWE was developed to assess pain and functioning in patients with DRFs [40]. The pain items were selected to represent the total spectrum of frequency and intensity. The function items were selected to represent a range of physical activities that require different ranges of motions or muscle strength capabilities. For both subscales the maximum score is 50 (most disability) and the minimum score is 0 (no disability). Although these subscales have been reported frequently in literature, it has been suggested that the PRWE measures a single dimensional trait, and a single (sum) score should be used [41]. The questionnaire has a good validity for symptoms and function of the wrist [42].

The Michigan Hand Outcomes Questionnaire (MHQ) assesses hand outcomes that are of importance to patients and specific for the impaired hand (left and right separately) and includes 6 subscales (general function, activities of general life, work, pain, esthetics and satisfaction). The subscale score is the sum of the outcome of each question and ranges from 0 to 100 . A higher score on the pain subscale indicates less pain. For the other five subscales and the total score higher scores imply a better function. The MHQ compares favourably with other PROs regarding upper extremity in the area of test-retest reliability, validity and responsiveness. In addition it has high internal consistency [43]. The strength of the MHQ is its multidimensional construct in measuring symptoms, function, aesthetics and satisfaction [43].

The SF-36 is developed to survey overall health status [44]. It contains 36 questions to assess limitations in (1) physical function, (2) role function, (3) social function, (4) bodily pain, (5) general mental health, (6) limitations in role function due to emotional problems, (7) vitality and (8) general health perception. Scale scores range from 0 to 100 with higher scores indicating a better health status. Scale scores can be used to calculate a physical and a mental component summary score [44]. Validity of this questionnaire is sufficient for groups reporting varying extents of illness-health [45].

\section{Work}

The intensity of executing work tasks was categorized according to the Dictionary of Occupational Titles (DOT) classification in sedentary, light, medium, heavy or very heavy work [46]. Patients filled in a short questionnaire to report change of work following the DRF and the reason for such a change.

\section{Statistics}

Data were assessed for normal distribution. Continuous data were presented as mean (standard deviation, SD) and as median (interquartile range, IQR) when no normal distribution of the data was present. The Chi squared test and Fisher's exact tests were used to analyze associations between dichotomous and/or categorical variables. $T$ tests were performed when analyzing continuous variables if a normal distribution was found. If data did not have a normal distribution, Mann-Whitney $U$ tests were used. One way ANOVA tests were performed when analyzing the association between continuous variables and categorical variables, Bonferroni posthoc analyses were performed afterwards. Multivariable linear regression analysis, using backward stepwise selection (until all $p$ values were $\leq 0.2$ ) was performed with PROs as an outcome and other factors (age, gender, AO/OTA fracture type, type of treatment, follow-up, flexion-extension arc of motion, grip strength and presence of PA) as explanatory variables. To be able to impute the categorical variable AO/OTA fracture type In regression analysis, 2 dummy variables were calculated with AO/OTA fracture type $\mathrm{A}$ as reference variable (dummy 1 is AO/OTA fracture type $\mathrm{B}=1$, other types $=0$; dummy 2 is $\mathrm{AO} / \mathrm{OTA}$ fracture type $\mathrm{C}=1$, other types $=0$ ). Level of significance was set at $p \leq 0.05$. All statistical analyses were performed using IBM SPSS, version 22.

\section{Results}

Eighty-four patients of the 433 eligible patients responded to the invitation to participate in the study of which 73 (32 women, $41 \mathrm{men}$ ) consented to participate with a mean age of 33.5 (SD 9.2) years at the time of the injury (participation rate 19\%) (Table 1). Participants suffered statisticaly significant more often from intra-articular fractures according to the AO foundation and Orthopaedic Trauma Association (AO/OTA) classification system than non-participants. Of the participants, $19.2 \%$ had type A fractures, $41.1 \%$ type B and $39.7 \%$ type $\mathrm{C}$ fractures. In contrast, of the non-participants $53.1 \%$ had type A fractures, $28.6 \%$ type B and $18.3 \%$ type $\mathrm{C}$ fractures $(p=0.013)$. No further differences between participants and non-participants were found.

\section{Prevalence of PA}

After a median follow up of 5 years (62.0 months) the prevalence of PA (grade I, II) was $32 \%$ (Table 1). Patients with PA were more often males (73.9\% versus $48.0 \%$ ) and statistically significant older (6.6 years) than patients without PA (Table 1). No statistically significant differences between patients with and without PA regarding trauma energy, type 
Table 1 Patient characteristics of the total population and differences between patients with and without PA

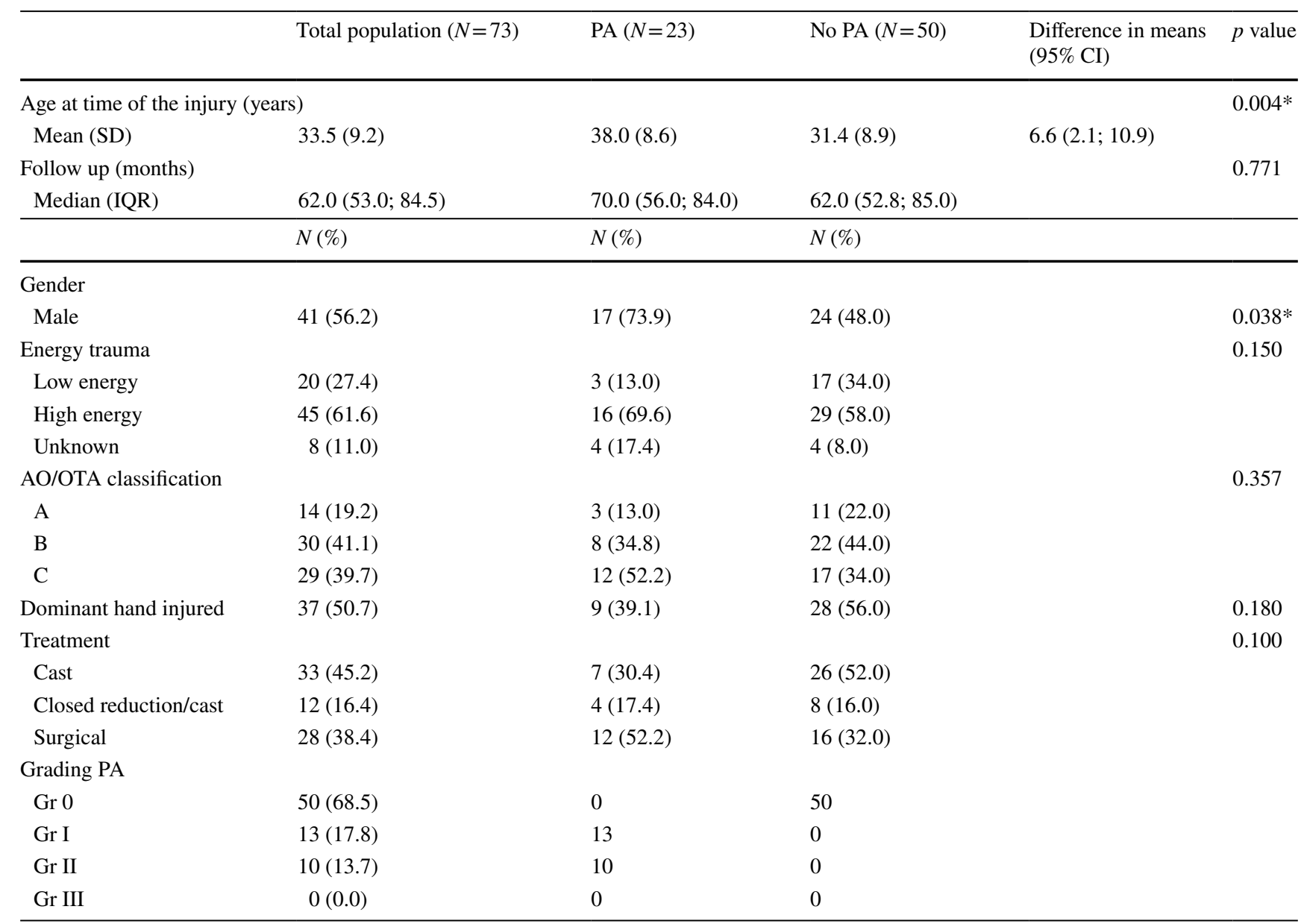

Results of independent samples $T$ test (age) and Chi-squared test (other variables)

$N$ number of patients, $S D$ standard deviation, $I Q R$ interquartile range, $P A$ posttraumatic arthritis, $95 \% C I 95 \%$ confidence interval, fracture type $\mathrm{A}, \mathrm{B}$ and $\mathrm{C}$ according to the $\mathrm{AO}$ foundation and Orthopaedic Trauma Association AO/OTA classification, $P A$ posttraumatic arthritis

*Statistical significance

of treatment, AO/OTA fracture classification or dominance were found (Table 1). Patients who were treated surgically, more often had AO/OTA type $\mathrm{C}$ fractures in comparison to patients who were treated conservatively (AO/OTA type A 1, type B 0 , type $\mathrm{C} 27$ surgically treated, AO/OTA type A 8 , type B 18 , type C 19 conservatively treated).

\section{PA and radiological measurements}

All radiological measurements were within normal ranges [31-36]. Between patients who were treated surgically and patients who were treated conservatively (with our without closed reduction), no statistically significant difference in radiological measurements were found at follow up. When comparing the radiological measurements of the injured to the uninjured wrist at follow up, only dorsal angulation was statistically significant more pronounced in the injured wrist $\left(-1.3^{\circ}\right.$ versus $\left.5.1^{\circ}, p<0.001\right)$ (Table 2). Patients with PA had a statistically significant longer radial length at follow up (13.7 $\mathrm{mm}$ versus $12.6 \mathrm{~mm}, p=0.045$ ) (Table 3). Also, the difference in radial length between the injured and uninjured wrist was greater in patients with PA ( 0.6 versus -0.6 , $p=0.024$ ). All other radiological measurements at follow up did not differ between the patients with and without PA (Table 3).

\section{CROs}

\section{Active range of motion}

Patients with PA had statistically significant diminished flexion/extension arc of motion $\left(12^{\circ}, p=0.008\right)$ and ulnar/ radial deviation arc of motion $\left(6.3^{\circ}, p=0.018\right)$ compared to patients without PA (Table 4).

AO/OTA fracture classification was not statistically significant associated with active range of motion (Table 5). 
Table 2 Radiological measurements at follow up compared with the measurements of the uninjured wrist at follow-up

\begin{tabular}{|c|c|c|c|c|c|c|c|}
\hline \multirow[t]{2}{*}{ Radiological factors } & \multirow[t]{2}{*}{$N$} & \multicolumn{2}{|c|}{$\begin{array}{l}\text { Follow up injured } \\
\text { wrist }\end{array}$} & \multicolumn{2}{|c|}{$\begin{array}{l}\text { Follow-up uninjured } \\
\text { wrist }\end{array}$} & \multirow[t]{2}{*}{ Mean difference (SD) } & \multirow{2}{*}{$\begin{array}{l}\text { Significance } \\
p(95 \% \text { CI of mean difference })\end{array}$} \\
\hline & & Mean & SD & Mean & SD & & \\
\hline Ulnar variance $(\mathrm{mm})$ & 73 & 0.9 & 1.8 & 0.4 & 1.6 & $0.4(1.9)$ & $0.063(-0.0 ; 0.9)$ \\
\hline Radial length (mm) & 73 & 13.0 & 2.1 & 13.2 & 2.1 & $-0.2(2.1)$ & $0.318(-0.7 ; 0.2)$ \\
\hline Radial inclination $\left(^{\circ}\right)$ & 73 & 25.5 & 3.6 & 26.4 & 3.8 & $-0.9(4.2)$ & $0.079(-1.9 ;-0.1)$ \\
\hline Dorsal angulation $\left(^{\circ}\right)$ & 73 & -1.3 & 6.6 & -5.1 & 4.1 & $3.8(6.5)$ & $<0.001(2.3 ; 5.3)^{*}$ \\
\hline SL distance (mm) & 45 & 2.1 & 0.4 & 2.0 & 0.4 & $0.1(0.5)$ & $0.099(-0.0 ; 0.3)$ \\
\hline DRUJ distance (mm) & 72 & 2.4 & 0.8 & 2.3 & 0.8 & $0.1(0.7)$ & $0.224(-0.1 ; 0.3)$ \\
\hline
\end{tabular}

Results of paired samples $T$ test

$N$ number of patients, $S D$ standard deviation, 95\% CI 95\% confidence interval, SL scapholunate ligament, DRUJ distal radioulnar Joint

*Significant difference

Table 3 Associations between radiological measurements and PA

\begin{tabular}{|c|c|c|c|c|c|}
\hline \multirow[t]{2}{*}{ Radiological factors } & \multicolumn{2}{|l|}{$\mathrm{PA}(N=23)$} & \multicolumn{2}{|l|}{ No PA $(N=50)$} & \multirow{2}{*}{$\begin{array}{l}\text { Significance } \\
p \text { (95\% CI of mean difference) }\end{array}$} \\
\hline & Mean & SD & Mean & SD & \\
\hline Ulnar variance $(\mathrm{mm})$ & $1.1(N=23)$ & 2.4 & $0.7(n=50)$ & 1.5 & $0.462(-1.5 ;-0.7)$ \\
\hline Radial length (mm) & $13.7(N=23)$ & 2.5 & $12.6(n=50)$ & 1.9 & $0.045^{*}(-2.1 ;-0.0)$ \\
\hline Radial inclination $\left(^{\circ}\right)$ & $25.6(N=23)$ & 4.4 & $25.5(n=50)$ & 3.2 & $0.888(-1.9 ; 1.7)$ \\
\hline Dorsal angulation $\left({ }^{\circ}\right)$ & $-2.2(N=23)$ & 8.0 & $-0.9(n=50)$ & 5.9 & $0.472(-2.4 ; 5.2)$ \\
\hline \multirow[t]{2}{*}{ SL distance $(\mathrm{mm})$} & $2.3(N=16)$ & 0.4 & $2.1(n=38)$ & 0.4 & $0.072(-0.4 ; 0.0)$ \\
\hline & Median & IQR & Median & IQR & $\begin{array}{l}\text { Mann-Whitney } U \\
p \text { value }\end{array}$ \\
\hline DRUJ distance $(\mathrm{mm})$ & $2.1(N 23)$ & $1.8 ; 2.9$ & $2.3(n=50)$ & $1.9 ; 2.8$ & 0.533 \\
\hline Step-off (mm) & $0.0(N=16)$ & $0.0 ; 0.0$ & $0.0(n=38)$ & $0.0 ; 0.0$ & 0.053 \\
\hline Gap (mm) & $0.0(N=15)$ & $0.0 ; 0.0$ & $0.0(n=39)$ & $0.0 ; 0.0$ & 0.177 \\
\hline
\end{tabular}

Outcome of Independent $T$ test and Mann-Whitney $U$

$N$ number of patients, $S D$ standard deviation, $95 \%$ CI 95\% confidence interval, SL scapholunate ligament, DRUJ distal radioulnar joint

*Significant difference

\section{Grip strength}

Compared to patients without PA, the grip strength and key pinch strength were $9.3 \%$ and respectively $8.8 \%$ weaker $(p=0.032$ and $p=0.015)$ in patients with PA (Table 4). However, when correcting for dominance with the $10 \%$ rule, no statistically significant differences in grip strength measurements are present between patients with and without PA (Table 4).

\section{PROs}

The median scores of the MHQ subscales: general functioning (65.0 compared to 75.0, $p=0.018$ ), esthetics (93.8 compared to $100.0, p=0.037)$ and satisfaction (75.0 compared to $91.7, p=0.042$ ) were statistically significant poorer in the patients with PA (Table 6). Also, the median total MHQ score was statistically significant poorer in patients with PA (83.0 compared to 90.5, $p=0.044$ ) (Table 4). Regarding the SF-36, physical functioning (median 95.0 versus 100.0, $p=0.028$ ) was statistically significant poorer in patients with PA.

\section{Regression analysis}

Flexion/extension arc of motion was a statistically significant explanatory variable for DASH, PRWE function and PRWE total. Although not statistically significant, flexion/extension arc of motion did seem to be an important explanatory variable for the PRWE pain and MHQ total (Table 7). Percentage of grip strength was an explanatory variable in the linear regression models of the total MHQ score. Type of treatment and AO/OTA fracture type were not statistically significant explanatory variables for all PROs. Regarding the regression 
Table 4 CROs: differences between patients with and without PA

\begin{tabular}{|c|c|c|c|c|}
\hline CROs & $\begin{array}{l}\text { PA }(N=23) \\
\text { Mean }(\mathrm{SD})\end{array}$ & $\begin{array}{l}\text { No PA }(N=50) \\
\text { Mean }(\mathrm{SD})\end{array}$ & Difference in means $(95 \% \mathrm{CI})$ & $p$ value \\
\hline \multicolumn{5}{|l|}{ Active range of motion $\left({ }^{\circ}\right)$} \\
\hline Flexion/extension arc & $133.1(17.8)$ & $145.1(17.3)$ & $12.0(3.2 ; 20.7)$ & $0.008^{*}$ \\
\hline Ulnar/radial deviation arc & $53.7(9.4)$ & $60.1(10.7)$ & $6.3(1.1 ; 11.5)$ & $0.018^{*}$ \\
\hline Pro/supination arc & $144.8(14.2)$ & $147.6(12.4)$ & $2.8(-3.7 ; 9.3)$ & 0.397 \\
\hline \multicolumn{5}{|c|}{ Grip strength not corrected for dominance ( $\%$ of the uninjured wrist) } \\
\hline Grip strength & $88.0(15.7)$ & $97.3(17.4)$ & $9.3(0.8 ; 17.8)$ & $0.032 *$ \\
\hline Sustained grip & $90.3(18.3)$ & $98.9(26.4)$ & $8.6(-3.6 ; 20.8)$ & 0.165 \\
\hline Key pinch strength & $89.4(18.0)$ & $98.2(11.6)$ & $8.8(0.4 ; 17.1)$ & $0.015^{*}$ \\
\hline \multicolumn{5}{|c|}{ Grip strength corrected for dominance ( $\%$ of the uninjured wrist) } \\
\hline Grip strength & $89.6(11.8)$ & $97.3(16.7)$ & $7.7(-.1 ; 15.4)$ & 0.052 \\
\hline Sustained grip & $92.2(17.9)$ & $98.7(28.5)$ & $6.5(-6.3 ; 19.4)$ & 0.315 \\
\hline Key pinch strength & $115.5(121.1)$ & $108.7(74.6)$ & $-6.8(-52.8 ; 39.2)$ & 0.769 \\
\hline
\end{tabular}

Results of independent samples $T$ test

$N$ number of patients, $S D$ standard deviation, $P A$ posttraumatic arthritis, $95 \% C I$ 95\% confidence interval

*Statistical significance

Table 5 Associations between AO/OTA classification and active range of motion

\begin{tabular}{|c|c|c|c|c|c|c|c|c|c|c|}
\hline \multirow[t]{2}{*}{ AO/OTA classification } & \multicolumn{4}{|c|}{$\begin{array}{l}\text { One way ANOVA } \\
\text { Active range of motion }\left(^{\circ}\right)\end{array}$} & \multicolumn{6}{|c|}{$\begin{array}{l}\text { Posthoc Bonferroni } \\
\text { Difference in means (SE) }\end{array}$} \\
\hline & $\begin{array}{l}\text { Type A } \\
\text { Mean (SD) }\end{array}$ & $\begin{array}{l}\text { Type B } \\
\text { Mean (SD) }\end{array}$ & $\begin{array}{l}\text { Type C } \\
\text { Mean (SD) }\end{array}$ & $p$ & A versus B & $p$ & A versus $C$ & $p$ & $\mathrm{~B}$ versus $\mathrm{C}$ & $p$ \\
\hline Flexion/extension arc & $150.1(17.0)$ & $139.1(19.2)$ & $139.2(16.9)$ & 0.128 & $11.0(5.8)$ & 0.074 & $10.9(5.8)$ & 0.434 & $-0.1(4.7)$ & 1.00 \\
\hline Ulnar/radial deviation arc & $56.7(9.8)$ & $57.6(12.2)$ & $59.2(9.7)$ & 0.742 & $-0.9(3.5)$ & 1.00 & $-2.5(3.5)$ & 1.00 & $-1.6(2.8)$ & 1.00 \\
\hline Pro/supination arc & $150.0(10.3)$ & $146.3(12.8)$ & $145.5(14.4)$ & 0.563 & $3.7(4.2)$ & 1.00 & $4.5(4.3)$ & 0.887 & $0.8(3.4)$ & 1.00 \\
\hline
\end{tabular}

Results of one way ANOVA and posthoc Bonferroni tests

$S D$ standard deviation, $S E$ standard error

analysis of the SF36 physical component score, all variables were removed, because no association with $p$ values $<0.200$ were present (Table 7).

\section{Work}

Seven patients (10\%) changed or left their occupation, all because of the DRF. Four of them had signs of PA. All of them changed to less demanding work or became unemployed. Change of occupation was more prevalent in patients in physically demanding jobs pre-injury; 3 of the 6 patients with heavy occupation (50\%), 2 of 18 patients with medium occupation (11\%), 1 of 15 with light occupation (7\%) and 1 of 29 patients with sedentary occupation (3\%) changed.

\section{Discussion}

A high prevalence of PA following a DRF in young nonosteoporotic patients was found (32\%). Patients with PA had statistically significant longer radial length than patients without PA. Within the group of patients with PA, radial length was also longer in comparison to the uninjured wrist. Patients healed with a residual gap more often had PA. PA was associated with diminished flexion/ extension arc of motion and ulnar/radial deviation arc of motion. Patients healed with a residual gap more often had PA. When corrected for dominance, no statistically significant differences in grip strength measurements between 
Table 6 PROs: differences between patients with and without PA

\begin{tabular}{|c|c|c|c|c|}
\hline PROs & $\begin{array}{l}\text { PA }(N=23) \\
\text { Median (IQR) }\end{array}$ & $\begin{array}{l}\text { No PA }(N=50) \\
\text { Median (IQR) }\end{array}$ & $\begin{array}{l}\text { Difference } \\
\text { in medians }\end{array}$ & $p$ value \\
\hline DASH & $6.7(2.5 ; 24.2)$ & $3.3(0.6 ; 11.8)$ & 3.4 & 0.094 \\
\hline \multicolumn{5}{|l|}{ PRWE } \\
\hline Pain & $8.0(0.0 ; 15.0)$ & $5.5(0.0 ; 14.5)$ & 2.5 & 0.661 \\
\hline Function & $10.0(2.0 ; 18.0)$ & $4.5(0.0 ; 12.0)$ & 5.5 & 0.187 \\
\hline Total & $13.0(3.5 ; 21.0)$ & $8.3(1.4 ; 20.1)$ & 4.7 & 0.424 \\
\hline \multicolumn{5}{|l|}{ MHQ } \\
\hline General function & $65.0(50.0 ; 80.0)$ & $75.0(65.0 ; 95.0)$ & 10.0 & $0.018^{*}$ \\
\hline Activities general life & $95.0(80.0 ; 100.0)$ & $100.0(85.0 ; 100.0)$ & 5.0 & 0.189 \\
\hline Work & $100.0(80.0 ; 100.0)$ & $95.0(88.8 ; 100.0)$ & 5.0 & 0.789 \\
\hline Pain & $85.0(75.0 ; 100.0)$ & $90.0(80.0 ; 100.0)$ & 5.0 & 0.248 \\
\hline Esthetics & $93.8(68.8 ; 100.0)$ & $100.0(93.8 ; 100.0)$ & 6.4 & $0.037 *$ \\
\hline Satisfaction & $75.0(41.7 ; 95.8)$ & $91.7(70.8 ; 100.0)$ & 16.7 & $0.042 *$ \\
\hline Total & $83.0(67.1 ; 91.0)$ & $90.5(81.0 ; 95.5)$ & 7.5 & $0.044 *$ \\
\hline \multicolumn{5}{|l|}{ SF-36 } \\
\hline Physical functioning & $95.0(75.0 ; 95.0)$ & $100.0(90.0 ; 100.0)$ & 5.0 & $0.028 *$ \\
\hline Social functioning & $100.0(87.5 ; 100.0)$ & $100.0(87.5 ; 100.0)$ & 0.0 & 0.889 \\
\hline Rolemodel physical problem & $100.0(50.0 ; 100.0)$ & $100.0(100.0 ; 100.0)$ & 0.0 & 0.226 \\
\hline Rolemodel emotional problem & $100.0(100.0 ; 100.0)$ & $100.0(100.0 ; 100.0)$ & 0.0 & 0.474 \\
\hline Mental health & $88.0(80.0 ; 92.0)$ & $84.0(75.0 ; 92.0)$ & 4.0 & 0.469 \\
\hline Vitality & $75.0(60.0 ; 85.0)$ & $70.4(60.0 ; 85.0)$ & 4.6 & 0.650 \\
\hline Pain & $89.8(67.3 ; 100.0)$ & $79.6(67.3 ; 100.0)$ & 10.2 & 0.942 \\
\hline General health experience & $80.0(65.0 ; 85.0)$ & $72.5(63.8 ; 85.0)$ & 7.5 & 0.277 \\
\hline Health change & $50.0(50.0 ; 50.0)$ & $50.0(50.0 ; 63.8)$ & 0.0 & 0.442 \\
\hline Physical component & $88.7(69.3 ; 95.0)$ & $88.4(81.0 ; 92.5)$ & 0.3 & 0.972 \\
\hline Mental component & $87.6(83.4 ; 94.3)$ & $89.2(79.1 ; 93.1)$ & 1.6 & 0.669 \\
\hline
\end{tabular}

Results of Mann-Whitney $U$ test

$N$ number of patients, $I Q R$ interquartile range, $P A$ posttraumatic arthritis, VAS Visual Analogue Scale, $D A S H$ disability of arm, shoulder and hand questionnaire, $P R W E$ patient rated wrist evaluation, $M H Q$ Michigan Hand Questionnaire, SF-36 Short Form (36) Health Survey

*Statistical significance

patients with and without PA are present. In patients with PA the subscales 'general functioning', 'esthetics' and 'satisfaction' from the MHQ questionnaire were statistically significant poorer, as was the total MHQ score and the physical functioning scale of the SF-36. The DASH, PRWE function and PRWE total were statistically significant impacted by flexion/extension arc of motion.

\section{Prevalence of PA}

The high prevalence of PA of $32 \%$ after a median follow-up of 5 years in this young population was surprising. Forward et al. presented a prevalence of $43 \%$ after a mean follow up of 38 years in non-osteoporotic patients at time of the injury [4]. The prevalence in our study might be overestimated due to the low response rate, as individuals with complaints might be more interested in participating in research activities. This assumption is supported by the fact that participants had sustained more intra-articular DRFs than non-participants. Further research on the prevalence of PA after DRFs in young patients is needed.

\section{Radiological measurements}

DRFs in non-osteoporotic patients mainly result from highenergy trauma and therefore frequently lead to intra-articular fractures [47]. Our results are supported by literature, suggesting that DRFs that healed with a residual gap and/or overall intra-articular incongruence of $\geq 2 \mathrm{~mm}$ are associated with early radiographic signs of PA [3, 4, 18, 48, 49]. In addition, a systematic review recently published by our research group established that other radiological predicting factors for PA such as radial length, radial inclination, dorsal angulation and ulnar variance are presented in literature with conflicting results [3]. Regarding radiological measurements, only radial length was $1.1 \mathrm{~mm}$ longer at follow up in patients with PA in comparison to patients without PA. All studies reporting on the influence of radial 
Table 7 Linear regression analyses regarding PROs and explanatory variables

\begin{tabular}{llll}
\hline Dependent & Explanatory variables & $\begin{array}{l}\text { Regression coefficient } \\
(\text { SE })\end{array}$ & $\begin{array}{l}p \text { value } \\
\text { of vari- } \\
\text { able }\end{array}$ \\
\hline DASH & Gender & $-4.5(2.8)$ & 0.112 \\
& Follow-up time & $-0.2(0.1)$ & 0.033 \\
PRWE pain & Flexion/extension arc & $-0.2(0.1)$ & 0.017 \\
& Follow-up time & $-0.1(0.1)$ & 0.076 \\
PRWE function & Flexion/extension arc & $-0.1(0.1)$ & 0.103 \\
& Gender & $-8.3(3.5)$ & 0.023 \\
PRWE total & Follow-up time & $-0.2(0.1)$ & 0.090 \\
& Flexion/extension arc & $-0.2(0.1)$ & 0.013 \\
MHQ total & Gender & $-5.8(4.1)$ & 0.164 \\
SF 36 physical component & Follow-up time & $-0.2(0.1)$ & 0.058 \\
SF 36 mental component & Flexion/extension arc & $-0.3(0.1)$ & 0.029 \\
\hline
\end{tabular}

$P R O$ patient rated outcome measure, $M H Q$ Michigan Hand Outcomes Questionnaire, $S F-36$ Short Form 36 questionnaire, $S E$ standard error, \% grip strength percentage grip strength of the affected compared to the non affected wrist length, reported on shortening of radial length. Most studies reported no statistically significant association with shortened radial length and the development of PA [1, 5, 50], except for Forward et al. [4]. The development of PA has multifactorial causes, such as increased stress on the articular surface that damages cells and matrices of articular cartilage and subchondral bone [2]. Overcorrection of the radial length can cause higher axial loading on the articular surface of the distal radius and therefore may contribute to the development of PA [51, 52]. In previous literature normal ranges for radiological factors have been described; ulnar variance -4 to $2 \mathrm{~mm}[31,32]$, radial length $8-17 \mathrm{~mm}$ [33], radial inclination $16^{\circ}-29^{\circ}[31,34]$, dorsal angulation 0 -palmar $22^{\circ}[35,36]$. All measurements in this study were within these normal ranges. Although radial length seems to influence the development of PA, more research regarding these radiological predicting factors for PA is mandatory to provide constructive conclusions. Common held beliefs are dictated by the findings stated earlier that anatomical reduction of articular surfaces and absolute stable internal fixation should be pursued. In this study, no statistically significant difference regarding presence of PA between patients who were treated conservatively and operatively was found. This could suggest that anatomical reduction was achieved when patients were treated surgically and little residual incongruence was present following treatment. The relatively short follow-up period (5 years) in our study should preferably be extended in further research to get insight in the "natural' course of PA in young patients with DRF. With regard to CROs, it has been reported that presence of PA did not influence aROM and grip strength after 15 year follow up [53]. However, the impact of PA after long term follow up on participation in societal roles and in the personal lives of these young people, captured with PROs remains unclear.

\section{CROs}

Patients with PA showed a diminished flexion/extension arc and ulnar/radial deviation arc of motion. It is known that residual articular incongruence affects aROM already after a follow up of 1 year [54]. Other authors have shown that patients can maintain a high level of functioning with PA [53]. Articular incongruency is the logical result from intra-articular fractures, however in our study no statistically significant association between fracture severity as depicted by the AO/OTA classification and active range of motion was found. In addition, associated intercarpal ligamentous injuries are known to influence active range of motion following DRFs and could be an explanation for the diminished active range of motion found in our study $[12,55]$.

Grip strength and key pinch strength of the injured side compared to the uninjured side seemed to be affected by PA. However, when correcting for dominance with the $10 \%$ rule, this statistically significant difference resides [37]. This finding supports literature emphasizing that grip strength is not a determinant of wrist function alone, but merely a reflection of overall muscle strength and condition of a chain of muscles in the upper limb [56]. We do believe that measurement of differences in grip strength between injured and uninjured side are relevant when determining follow-up outcomes of 
patients who sustained a DRF. Minimal detectable change (MDC) is defined as the smallest amount of change between two measurements that indicates a real change in measurement and not being a change due to measurement error [57]. This is a statistical measurement and does not take into account change as experienced by patients. Minimal clinically important difference (MCID) is the smallest change in a measurement that a patient would notice [57]. For grip strength MDC has been reported to be $6.5 \mathrm{~kg}$ and MCID $19.5 \%$ or $6.5 \mathrm{~kg}$ in patients 1 year following surgery for DRFs [58]. This suggests that the grip strength measurements between patients with and without PA presented in our study after a median follow up duration of 5.2 years are not noticeable for patients and therefore are possibly not clinically relevant. However, since PA is a chronic, progressive disorder, grip strength differences may become clinically relevant after a longer follow-up time. Further research is needed to provide more insight in this issue.

\section{PROs}

Pain did not differ statistically significant between patients with or without PA suggesting that pain may not be the main problem non-osteoporotic patients are facing following a DRF. In patients suffering from hand osteoarthritis pain intensity does not correlate strongly with radiographic classification [59]. The fact that the level of pain was similar in both groups might be explained by the relatively short follow-up period. However, the follow up duration was long enough to show a significantly decreased active range of motion in patients with PA compared to patients without PA. This suggests that evaluation of young patients with DRFs should not only be guided by pain but also by other domains.

Another interesting finding of the application of the different PROs was that performance of activities in daily life and work, as measured by the DASH and PRWE, questionnaires specifically designed for upper extremity functioning, was similar in patients with PA compared to those without PA. In contrast, general functioning, esthetics and satisfaction as measured by the MHQ subscales were statistically significant lower in patients with PA, as was the subscale physical functioning in the SF-36 and the total MHQ score. For future research these findings imply that other dimensions, different from those measured by the commonly used PRWE and DASH should be evaluated when measuring consequences of PA in patients with DRFs. MDC and MCID have been described to be respectively 7.7 and 17.3 for PRWE and 9.3 and 13.8 points for DASH [60]. For the MHQ none of the domains were reported to be discriminative after 3 years following volar plate fixation for DRFs, but for patients with carpal tunnel syndrome, MCIDs of 23, 13 and 8 were identified for the pain, function and work domains, respectively [61]. This suggests that the difference reported in this study in general function domain between patients with and without PA $(10.0, p=0.018)$ might not be relevant for patients. However, the study by Shauver et al. described 12 points difference on the satisfaction domain to differentiate between satisfied and unsatisfied patients. Therefore, the difference between patients with and without PA regarding the satisfaction domain $(16.7, p=0.044)$ might be clinically relevant. Unfortunately, no MDC or MCID have been described for the domains of the SF-36. It is surprising that the more subjective domains such as esthetics and satisfaction were statistically significant associated with PA and not the domains reporting on pain and (daily) functioning. The impact of PA for patients following DRFs in everyday life, while there is limited aROM, does not seem to be significant. However patients with PA are less satisfied. Further research should clarify the specific reasons for dissatisfaction.

Waljee et al. recently described a core set of domains that should be reported in order to get insight into outcomes after a DRF for clinical or research purposes: performance, PROs, pain, complications and radiographs [62]. Domains found in our study to be statistically significant different between participants with and without PA such as satisfaction and esthetics, are however lacking in this core set. To report about patient satisfaction is becoming increasingly important, since in modern medicine patient-centered health care is emphasized. Decision making in healthcare has shifted from a paternalistic model to informed decision-making and shared decision-making. There is evidence suggesting that shared decision-making does facilitate positive health outcomes and improves satisfaction [63]. In the future, it might be beneficial to further explore which elements of Waljee's proposed core set are relevant in the clinical follow up of non-osteoporotic patients following DRFs [62, 64]. With regard to the PROs, we recommend the use of the MHQ subscales in clinical practice and post-injury DRF research, as this instrument seems to distinguish between patients with or without PA in the univariate analyses.

In literature, the few studies reporting on associations between CROs and PROs following DRFs describe these results at short-term follow up [65-68]. Chung et al. use two questions of the MHQ subscale satisfaction regarding range of motion and grip strength to determine cut-off points for satisfaction 3 month following a DRF. Optimal cut-points to distinguish satisfaction from dissatisfaction were met when patients recovered $65 \%$ of their grip strength and $95 \%$ of the wrist arc of motion [65]. Shauver et al. describe linear regression analyses revealing that 3 months following a DRF, patient's education, income, age at time of surgery and all measured outcome variables (grip strength difference, pinch strength difference, flexion, extension, active arc of motion, ulnar deviation, radial deviation, pronation, supination) accounted for $37 \%$ of the explained variance in 
total MHQ score [66]. Souer et al. describe a model where independent predictors pain $(F=61.16, p<0.001)$ and forearm rotation $(F=27.39, p<0.001)$ account for $71 \%$ of the explained variance of the DASH at a median follow-up of 6 months [68]. Our results support the finding that especially active range of motion is an important determinant of PROs. Type of treatment and AO/OTA fracture type did not seem to influence PROs. In addition, the influence of predicting factors seems to become less prominent with a longer follow-up duration as the explained variance in our study was lower than the earlier mentioned studies [66, 68]. Future research should be aimed at determining a complete overview of factors influencing PROs following DRFs in non-osteoporotic patients at early, but also at longer follow-up period. From our study, we conclude that the development of PA impacts active range of motion. Patients perceive diminished general functioning and satisfaction following PA and diminished active range of motion. This insight could direct rehabilitation strategies and can be used to counsel these patients on expected outcome.

Our results reporting $10 \%$ change of occupation following a DRF are likely to be of major interest for patients. No statistically significant association with PA was found. Although all patients reported to have changed occupation because of the injury, this percentage might be a normal change of occupation in this population. It is striking however that all patients changed to a physically less demanding occupation and change of occupation occurred more often in physically demanding jobs. This suggests that patients more often need to adapt their working environment following a DRF when having a physically demanding occupation.

\section{Strengths and weaknesses}

Where most studies report on osteoporotic patients, sometimes combined with non-osteoporotic patients, we report on a young non-osteoporotic population who sustained a DRF 4-11 years ago. As such, we contribute to the knowledge PA and its association with radiological measurements, CROs and PROs in young patients. In addition, we have used measurements of the uninjured wrist as control when calculating the percentage of grip strength. Large variations between patients are accounted for in this way. The active range of motion and grip strength measurements were performed by one hand therapist for consistency. Measurements were performed in a fixed sequence. As a consequence however, fatigue effects may have influenced our results. In future research, a random sequence of measurements should be considered. Intraobserver and interobserver variability of radiological measurements and AO/OTA fracture classifications of DRFs on radiographs is known to be moderate $[29,69]$. To eliminate interobserver variability, all measurements on radiographs were performed by one specialized radiologist. It has to be acknowledged that, although all radiographs have been performed according to protocol, measurement accuracy can be influenced by the quality of the radiograph taken and computed tomography could be more sensitive. The patients in our study did not have radiographic measurements out of normal ranges as described in literature [31-36]. Still, a prevalence of 32\% PA at a relatively short follow up duration of 5 years is a substantial portion and is likely to progress with longer follow up duration. Our response rate was low, presumably because this population is young and has moved for study or work purposes and therefore many current addresses could not be retrieved. The included number of 73 patients might be insufficient to draw firm conclusions. However, in most studies describing populations after DRF the number of patients included in this study is not exceeded $[10,65,70,71]$. Moreover those studies do not report response rates $[4,18,20,48]$. Our results contribute to the knowledge on how to improve outcome and diminish PA in the future. However, studies with longer follow up duration are mandatory to gain more insight in the influence of progressed PA on outcome.

\section{Conclusion}

Non-osteoporotic patients had a considerably high prevalence of PA following DRFs, despite relatively short followup time. Correction of radial length should be performed as precise as possible, as overcorrection may induce PA. PA is associated with diminished flexion/extension and ulnar/ radial deviation, irrespective of AO/OTA fracture type. Grip strength seems to be merely a determinant of strength and condition of the complete upper arm, as radiological measurements and PA does not seem to influence it. Nonosteoporotic patients following DRFs perceived diminished general functioning and dissatisfaction, which was impacted by the diminished active range of motion. Pain or impaired general health status were not reported. The PRO MHQ might be a valuable evaluation tool in this patient group. Change of occupation following DRFs should receive attention in further research.

Funding There is no funding source.

\section{Compliance with ethical standards}

Conflict of interest The authors declare that they have no conflict of interest.

Ethical approval The study was performed at a level II trauma center in the Netherlands and was approved by the local Medical Ethics Committee (NL41587.099.13) and registered at the Dutch Trial Bureau (TC 4002). 
Informed consent Informed consent was obtained from all individual participants.

Open Access This article is distributed under the terms of the Creative Commons Attribution 4.0 International License (http://creativeco mmons.org/licenses/by/4.0/), which permits unrestricted use, distribution, and reproduction in any medium, provided you give appropriate credit to the original author(s) and the source, provide a link to the Creative Commons license, and indicate if changes were made.

\section{References}

1. Knirk JL, Jupiter JB (1986) Intra-articular fractures of the distal end of the radius in young adults. J Bone Jt Surg Am 68(5):647-659

2. Giannoudis PV, Tzioupis C, Papathanassopoulos A, Obakponovwe O, Roberts C (2010) Articular step-off and risk of posttraumatic osteoarthritis. Evidence today. Injury 41(10):986-995

3. Lameijer CM, Ten Duis HJ, Dusseldorp IV, Dijkstra PU, van der Sluis CK (2017) Prevalence of posttraumatic arthritis and the association with outcome measures following distal radius fractures in non-osteoporotic patients: a systematic review. Arch Orthop Trauma Surg 137(11):1499-1513

4. Forward DP, Davis TR, Sithole JS (2008) Do young patients with malunited fractures of the distal radius inevitably develop symptomatic post-traumatic osteoarthritis? J Bone Jt Surg Br 90(5):629-637

5. Lindau T, Hagberg L, Adlercreutz C, Jonsson K, Aspenberg P (2000) Distal radioulnar instability is an independent worsening factor in distal radial fractures. Clin Orthop Relat Res 376:229-235

6. Lutz M, Arora R, Krappinger D, Wambacher M, Rieger M, Pechlaner S (2011) Arthritis predicting factors in distal intraarticular radius fractures. Arch Orthop Trauma Surg 131(8):1121-1126

7. Catalano LW 3rd, Cole RJ, Gelberman RH, Evanoff BA, Gilula LA, Borrelli J Jr (1997 Displaced intra-articular fractures of the distal aspect of the radius. Long-term results in young adults after open reduction and internal fixation. J Bone Jt Surg Am 79(9):1290-1302

8. Doi K, Hattori Y, Otsuka K, Abe Y, Yamamoto H (1999) Intraarticular fractures of the distal aspect of the radius: Arthroscopically assisted reduction compared with open reduction and internal fixation. J Bone Jt Surg Ser A 81(8):1093-1110

9. Fernandez DL (2000) Should anatomic reduction be pursued in distal radial fractures? J Hand Surg Br 25(6):523-527

10. Fitoussi F, Ip WY, Chow SP (1997) Treatment of displaced intraarticular fractures of the distal end of the radius with plates. $\mathrm{J}$ BONE JT SURG SER A 79(9):1303-1312

11. Strange-Vognsen H (1991) Intraarticular fractures of the distal end of the radius in young adults: a $16(2-26)$ year follow-up of 42 patients. Acta Orthop Scand 62(6):527-530

12. Forward DP, Lindau TR, Melsom DS (2007 Nov) Intercarpal ligament injuries associated with fractures of the distal part of the radius. J Bone Jt Surg Am 89(11):2334-2340

13. Lindau T, Runnquist K, Aspenberg P (2002) Patients with laxity of the distal radioulnar joint after distal radial fractures have impaired function, but no loss of strength. Acta Orthop Scand 73(2):151-156

14. Kwok IH, Leung F, Yuen G (2011) Assessing results after distal radius fracture treatment: a comparison of objective and subjective tools. Geriatr Orthop Surg Rehabil 2(4):155-160
15. Sharma H, Khare GN, Singh S, Ramaswamy AG, Kumaraswamy $\mathrm{V}$, Singh AK (2014) Outcomes and complications of fractures of distal radius (AO type $\mathrm{B}$ and $\mathrm{C}$ ): volar plating versus nonoperative treatment. J Orthop Sci 19(4):537-544

16. Ring D, Prommersberger K, Jupiter JB (2004) Combined dorsal and volar plate fixation of complex fractures of the distal part of the radius. J Bone Jt Surg Am 86-A(8):1646-1652

17. Gruber G, Zacherl M, Giessauf C, Glehr M, Fuerst F, Liebmann W et al (2010) Quality of life after volar plate fixation of articular fractures of the distal part of the radius. J Bone Jt Surg Ser A 92(5):1170-1178

18. Catalano IIILW, Cole RJ, Gelberman RH, Evanoff BA, Gilula LA, Borrelli J Jr (1997) Displaced intra-articular fractures of the distal aspect of the radius: long-term results in young adults after open reduction and internal fixation. J Bone Jt Surg Ser A 79(9):1290-1302

19. Bolmers A, Luiten WE, Doornberg JN, Brouwer KM, Goslings JC, Ring D et al (2013) A comparison of the long-term outcome of partial articular (AO type B) and complete articular (AO type C) distal radius fractures. J Hand Surg (USA) 38(4):753-759

20. Espen D (2003) Combined palmar and dorsal approach for complex distal radius fractures. Handchir Mikrochir Plast Chir 35(1):22-30

21. Nordvall H, Glanberg-Persson G, Lysholm J (2007) Are distal radius fractures due to fragility or to falls? A consecutive casecontrol study of bone mineral density, tendency to fall, risk factors for osteoporosis, and health-related quality of life. Acta Orthop 78(2):271-277

22. Van Son MA, De Vries J, Roukema JA, Den Oudsten BL (2013 Nov) Health status and (health-related) quality of life during the recovery of distal radius fractures: a systematic review. Qual Life Res 22(9):2399-2416

23. Handoll HH, Madhok R (2003) Surgical interventions for treating distal radial fractures in adults. Cochrane Database Syst Rev 3:CD003209

24. Handoll HH, Elliott $\mathbf{J}$ (2015) Rehabilitation for distal radial fractures in adults. Cochrane Database Syst Rev 25(9):CD003324

25. Cauley JA (2013) Public health impact of osteoporosis. J Gerontol A Biol Sci Med Sci 68(10):1243-1251

26. Dawson-Hughes B, Looker AC, Tosteson AN, Johansson H, Kanis JA, Melton LJ 3rd (2010) The potential impact of new National Osteoporosis Foundation guidance on treatment patterns. Osteoporos Int 21(1):41-52

27. Harvey N, Dennison E, Cooper C (2010) Osteoporosis: impact on health and economics. Nat Rev Rheumatol 6(2):99-105

28. van der Linden W, Ericson R (1981) Colles' fracture. How should its displacement be measured and how should it be immobilized? J Bone Jt Surg Am 63(8):1285-1288

29. Kreder HJ, Hanel DP, McKee M, Jupiter J, McGillivary G, Swiontkowski MF (1996 Jan) X-ray film measurements for healed distal radius fractures. J Hand Surg Am 21(1):31-39

30. Taleisnik J, Watson HK (1984) Midcarpal instability caused by malunited fractures of the distal radius. J Hand Surg Am 9(3):350-357

31. Schuind FA, Linscheid RL, An KN, Chao EY (1992 Oct) A normal data base of posteroanterior roentgenographic measurements of the wrist. J Bone Jt Surg Am 74(9):1418-1429

32. Palmer AK, Glisson RR, Werner FW (1982) Ulnar variance determination. J Hand Surg Am 7(4):376-379

33. Solgaard S (1984) Angle of inclination of the articular surface of the distal radius. Radiologe 24(7):346-348

34. Friberg S, Lundstrom B (1976) Radiographic measurements of the radio-carpal joint in normal adults. Acta Radiol Diagn (Stockh) 17(2):249-256 
35. Altissimi M, Antenucci R, Fiacca C, Mancini GB (1986) Longterm results of conservative treatment of fractures of the distal radius. Clin Orthop Relat Res 206:202-210

36. Metz VM, Gilula LA (1993) Imaging techniques for distal radius fractures and related injuries. Orthop Clin N Am 24(2):217-228

37. Petersen P, Petrick M, Connor H, Conklin D (1989) Grip strength and hand dominance: challenging the $10 \%$ rule. Am J Occup Ther 43(7):444-447

38. Baltzer H, Novak CB, McCabe SJ (2014) A scoping review of disabilities of the arm, shoulder, and hand scores for hand and wrist conditions. J Hand Surg Am 39(12):2472-2480

39. Beaton DE, Katz JN, Fossel AH, Wright JG, Tarasuk V, Bombardier C (2001) Measuring the whole or the parts? Validity, reliability, and responsiveness of the disabilities of the arm, shoulder and hand outcome measure in different regions of the upper extremity. J Hand Ther 14(2):128-146

40. MacDermid JC, Turgeon T, Richards RS, Beadle M, Roth JH (1998) Patient rating of wrist pain and disability: a reliable and valid measurement tool. J Orthop Trauma 12(8):577-586

41. El Moumni M, Van Eck ME, Wendt KW, Reininga IH, Mokkink LB (2016) Structural validity of the Dutch version of the patientrated wrist evaluation (PRWE-NL) in patients with hand and wrist injuries. Phys Ther 96(6):908-916

42. MacDermid JC, Tottenham V (2004) Responsiveness of the disability of the arm, shoulder, and hand (DASH) and patient-rated wrist/hand evaluation (PRWHE) in evaluating change after hand therapy. J Hand Ther 17(1):18-23

43. Shauver MJ, Chung KC (2013) The Michigan hand outcomes questionnaire after 15 years of field trial. Plast Reconstr Surg 131(5):779e-87e

44. Ware JE, Kosinski M (2001) Interpreting SF-36 summary health measures: a response. Qual Life Res 10(5):405-413 (discussion 415-20)

45. Jenkinson C, Coulter A, Wright L (1993) Short form 36 (SF36) health survey questionnaire: normative data for adults of working age. BMJ 306(6890):1437-1440

46. National Academy of Sciences, Committee on Occupational Classification and Analysis (1981) Dictionary of occupational titles (DOT): part I-current population survey April 1971, augmented with dot characteristics, and part II-Fourth edition dictionary of dot scores for 1970 census categories. U.S. Department of Commerce, Washington, DC (Ann Arbor, MI: Inter-university Consortium for Political and Social Research [distributor])

47. Handoll HH, Huntley JS, Madhok R (2008) Different methods of external fixation for treating distal radial fractures in adults. Cochrane Database Syst Rev 23(1):CD006522

48. Fernandez JJ, Gruen GS, Herndon JH (1997) Outcome of distal radius fractures using the short form 36 health survey. Clin Orthop Relat Res 341:36-41

49. Kopylov P, Johnell O, Redlund-Johnell I, Bengner U (1993) Fractures of the distal end of the radius in young adults: a 30-year follow-up. J Hand Surg Br 18(1):45-49

50. Lutz M, Arora R, Smekal V, Krappinger D, Gschwentner M, Rieger $\mathrm{M}$ et al (2007) Long-term results following ORIF of dorsal dislocated distal intraarticular radius fractures. Handchir Mikrochir Plast Chir 39(1):54-59

51. Brink PR, Rikli DA (2016) Four-corner concept: CT-based assessment of fracture patterns in distal radius. J Wrist Surg 5(2):147-151

52. Rikli DA, Honigmann P, Babst R, Cristalli A, Morlock MM, Mittlmeier $T$ (2007) Intra-articular pressure measurement in the radioulnocarpal joint using a novel sensor: in vitro and in vivo results. J Hand Surg Am 32(1):67-75

53. Goldfarb CA, Rudzki JR, Catalano LW, Hughes M, Borrelli J Jr (2006) Fifteen-year outcome of displaced intra-articular fractures of the distal radius. J Hand Surg (USA) 31(4):633-639
54. Karnezis IA, Panagiotopoulos E, Tyllianakis M, Megas P, Lambiris E (2005) Correlation between radiological parameters and patient-rated wrist dysfunction following fractures of the distal radius. Injury 36(12):1435-1439

55. Varitimidis SE, Basdekis GK, Dailiana ZH, Hantes ME, Bargiotas K, Malizos K (2008) Treatment of intra-articular fractures of the distal radius: fluoroscopic or arthroscopic reduction? J Bone Jt Surg Br 90(6):778-785

56. Leong DP, Teo KK, Rangarajan S, Lopez-Jaramillo P, Avezum A Jr, Orlandini A et al (2015) Prognostic value of grip strength: findings from the prospective urban rural epidemiology (PURE) study. Lancet 386(9990):266-273

57. Stratford PW, Binkley JM, Riddle DL (1996) Health status measures: strategies and analytic methods for assessing change scores. Phys Ther 76(10):1109-1123

58. Kim JK, Park MG, Shin SJ (2014) What is the minimum clinically important difference in grip strength? Clin Orthop Relat Res 472(8):2536-2541

59. Slatkowsky-Christensen B, Mowinckel P, Loge JH, Kvien TK (2007) Health-related quality of life in women with symptomatic hand osteoarthritis: a comparison with rheumatoid arthritis patients, healthy controls, and normative data. Arthritis Rheum 57(8):1404-1409

60. Kim JK, Park ES (2013) Comparative responsiveness and minimal clinically important differences for idiopathic ulnar impaction syndrome. Clin Orthop Relat Res 471(5):1406-1411

61. Shauver MJ, Chung KC (2009) The minimal clinically important difference of the Michigan hand outcomes questionnaire. J Hand Surg Am 34(3):509-514

62. Waljee JF, Ladd A, MacDermid JC, Rozental TD, Wolfe SW, Distal Radius Outcomes Consortium (2016) A unified approach to outcomes assessment for distal radius fractures. J Hand Surg Am 41(4):565-573

63. Truglio-Londrigan M, Slyer JT, Singleton JK, Worral P (2012) A qualitative systematic review of internal and external influences on shared decision-making in all health care settings. JBI Libr Syst Rev 10(58):4633-4646

64. Geneva $Z$ (2001) International classification of functioning, disability, and health (ICF). World Health Organization, Geneva

65. Chung KC, Haas A (2009) Relationship between patient satisfaction and objective functional outcome after surgical treatment for distal radius fractures. J Hand Ther 22(4):302-307 (quiz 308)

66. Shauver MJ, Chang KW, Chung KC (2014) Contribution of functional parameters to patient-rated outcomes after surgical treatment of distal radius fractures. J Hand Surg Am 39(3):436-442

67. Goldhahn J, Beaton D, Ladd A, Macdermid J, Hoang-Kim A, Distal Radius Working Group of the International Society for Fracture Repair (ISFR) et al. (2014) Recommendation for measuring clinical outcome in distal radius fractures: a core set of domains for standardized reporting in clinical practice and research. Arch Orthop Trauma Surg 134(2):197-205

68. Souer JS, Lozano-Calderon SA, Ring D (2008) Predictors of wrist function and health status after operative treatment of fractures of the distal radius. J Hand Surg Am 33(2):157-163

69. Ploegmakers JJW, Mader K, Pennig D, Verheyen CCPM (2007) Four distal radial fracture classification systems tested amongst a large panel of Dutch trauma surgeons. Injury 38(11):1268-1272

70. Beyermann K, Prommersberger K (2000) Reconstruction of comminuted distal radius fractures using a combined dorsal and palmar approach. Handchir Mikrochir Plast Chir 32(6):404-410

71. Jupiter JB, Lipton H (1993) The operative treatment of intraarticular fractures of the distal radius. Clin Orthop Relat Res 292:48-61 


\section{Affiliations}

\section{M. Lameijer ${ }^{1}$ - H. J. ten Duis ${ }^{1}$ - D. Vroling ${ }^{2}$ - M. T. Hartlief ${ }^{2}$ - M. El Moumni ${ }^{1}$. C. K. van der Sluis ${ }^{3}$}

1 Department of Trauma Surgery, University Medical Center Groningen, University of Groningen, Postbox 30.001,

Huispostcode BA51, 9700 RB Groningen, The Netherlands

2 Rehabilitation Center 'Revalidatie Friesland', Leeuwarden, The Netherlands
3 Department of Rehabilitation Medicine, University Medical Center Groningen, University of Groningen, Groningen, The Netherlands 